\title{
Phytophthora cinnamomi as a Cause of Oak Mortality in the State of Colima, Mexico
}

\author{
F. H. Tainter, Department of Forest Resources, Clemson University, Clemson, SC 29634-0331; J. G. O'Brien, \\ USDA Forest Service, 1992 Fowell Ave., St. Paul, MN 55108; A. Hernández, Secretaría de Medio Ambiente, Re- \\ cursos Naturales y Pesca, Progreso No. 5, Col. de Carmen, Coyoacan, c.p. 04110, México, D.F.; F. Orozco, Secre- \\ taría de Medio Ambiente, Recursos Naturales y Pesca, Victoria No. 360, Colima, Colima, México; and O. Re- \\ bolledo, Universidad de Colima, Tecoman, Colima, AP 36, México
}

\begin{abstract}
Tainter, F. H., O’Brien, J. G., Hernández, A., Orozco, F., and Rebolledo, O. 2000. Phytophthora cinnamomi as a cause of oak mortality in the state of Colima, Mexico. Plant Dis. 84:394-398.

This research identifies the root pathogen Phytophthora cinnamomi as the primary cause of mortality in a 300-ha disease center of mixed oak trees in a native forest in southern Mexico. In increasing order of apparent field resistance to the disease, the major oak species are Quercus glaucoides, $Q$. peduncularis, and $Q$. salicifolia. $P$. cinnamomi was isolated from soil in the affected area from symptomatic trees and was successfully used to perform Koch's postulates on these three oak species. Artificial and natural infections produced vertically elongated discolorations in the outer xylem and distinctive phloem canker lesions with a sharp demarcation line between healthy and affected tissues. In $Q$. glaucoides there is little evidence that this oak species is able to resist the girdling effects of the phloem lesions, but in $Q$. peduncularis, and especially in $Q$. salicifolia, increased production of callus tissue around the phloem canker lesions suggests an active resistance mechanism that may allow these infected trees to survive somewhat longer. This particular incident is unlike other recent reports in other parts of the world of oak mortality caused by $P$. cinnamomi because the initial appearance of disease in this area is known (just prior to 1987), and it has subsequently expanded to the present area of 300 ha (in 1999) as a distinctive infection locus with periodically advancing infection fronts. This incident is also another dramatic illustration of the potential environmental damage that can result when P. cinnamomi is introduced into a simple forest ecosystem where the major overstory trees are susceptible to infection and are killed.
\end{abstract}

Additional keywords: introduced pathogen, root disease

A severe outbreak of oak mortality was first observed in 1987 in the ejido of El Arrayanal near the city of Colima, state of Colima, and $560 \mathrm{~km}$ west of Mexico City (Fig. 1A and B). An ejido is a kind of landbased cooperative, established under federal guidance, in which the residents collectively own the land and work with pooled resources. In this ejido, subsistence agriculture is the primary activity, with charcoal production used to generate capital.

Because of the increasing size of the affected area, in 1991, representatives of the ejido requested technical assistance from the Secretaría de Medio Ambiente, Recursos Naturales y Pesca (SEMARNAP) staff

Corresponding author: F. H. Tainter

E-mail: ftntr@clemson.edu

Accepted for publication 7 December 1999

Publication no. D-2000-0131-02S

(c) 2000 The American Phytopathological Society located in the city of Colima. In 1992, Mexican authorities requested technical assistance to determine the cause of the mortality. By that time, the mortality had spread southwesterly and affected about 50 ha of oak forest (Figs. 1 and 2A). SEMARNAP authorities were especially concerned that the oak wilt pathogen, Ceratocystis fagacearum (Bretz) Hunt, may have spread into Mexico from Texas, where oak wilt had increased in importance since the 1960s. Surveys in the area were made in 1992, 1993, 1994, 1995, and 1997. The mortality continued to spread west and east, and the affected area grew to 150 ha in 1993 and to 180 ha in 1994. By 1995, the mortality had reached the edge of the forest in the west and north of the village of El Arrayanal but continued to spread eastward. The affected area had increased to 200 ha, and a great deal of oak tree mortality had occurred. The mortality abruptly stopped spreading toward the south at the boundary between the oakdominated forest and a mesic tropical hardwood forest. By 1997, the affected area had increased to at least 300 ha, and it is presently spreading eastward into unaffected oak forest, progressing both uphill and across streams. The terrain is hilly and very rocky, and the shallow soils are heavy clays.

The three oak species prevalent in the area are Quercus glaucoides, Q. peduncularis, and $Q$. salicifolia. With the onset of symptoms, $Q$. glaucoides declines rapidly and within several weeks to several months dies, whereas $Q$. salicifolia takes months, or more usually, several years to die after the first appearance of foliar symptoms. The behavior of $Q$. peduncularis is intermediate between the other two oak species. Nance (Byrsonima crassifolia), a shrubby understory species, disappeared from the affected area during the early part of the mortality episode.

Symptoms on affected oaks include foliar interveinal chlorosis and necrosis (Fig. 2B), wilt, dieback, and discolorations in the phloem-xylem. Foliar discoloration is transitory, and the leaves are either cast or necrose and remain attached for a time after the tree dies. Despite several attempts, the oak wilt pathogen, C. fagacearum, has not been isolated from symptomatic trees.

Residents described their initial observations on the mortality as a moving front that originated near a residence in the village and moved first toward the southwest for several years, then moved west and east for several more years, and then finally moved only toward the east (Fig. 1). In the first two directions, the front stopped when it confronted a change in either soil type or vegetation. Presently, the front is moving toward a vast natural oak forest composed largely of the three oak species known to be susceptible to the mortality. There do not appear to be any obstacles in the path of the expanding epiphytotic to the east.

During the 1995 survey, bleeding cankers were observed on several of the affected oaks. After removal of the outer bark, a distinctive canker-like symptom consisting of dark red phloem delimited by a black zone line was observed. The cankers resembled cankers of ink disease pro- 
duced on North American oaks inoculated with the root pathogen Phytophthora cinnamomi Rands (4). In 1997, we attempted to isolate specific primary root pathogens (including $P$. cinnamomi) and determine their possible involvement in the oak mortality.

\section{MATERIALS AND METHODS}

Field survey. A total of 19 soil samples of approximately $20 \mathrm{~g}$ each were collected from six sample points (Fig. 1B) within the decline area in July 1997, each sample from the vicinity of a tree (15 total) with visible foliar symptoms. The samples were divided in half, with half subsequently analyzed in Mexico and half at Clemson University. The same isolation procedure was followed at both locations. Soil dilu- tions were based on the procedure of Hornby and Ullstrup (3), except that $0.2 \%$ water agar was used in place of $1 \%$ sodium carboxymethy cellulose as the diluent. Plating was on pimaricin-chloramphenicolhymexazol (PCH) selective medium (10). All plates were read 3 weeks after plating, colonies of Pythiaceous fungi were subcultured, and tentative identifications were made.

Greenhouse inoculation trial. Six 12month-old seedlings of $Q$. glaucoides grown in 1-gal pots in Fafard no. 3F potting medium were inoculated with a $3-\mathrm{mm}$ agar plug of the Mexican isolate of $P$. cinnamomi (designated Mex. 12) grown for 14 days on acidified potato dextrose agar in a small wound created on a major root by slicing through the bark into the xylem to create an 8-mm-long flap of bark and outer xylem. Three additional seedlings were similarly wounded but inoculated only with a sterile agar plug. All inoculation sites were wrapped with several layers of Parafilm, and the seedlings were replanted in the pots. Plants were incubated for 18 days, observed for symptoms, and tissue chips from the inoculated areas, and resulting lesions, were plated onto $\mathrm{PCH}$ medium.

Field inoculation trials. Twelve apparently healthy trees each of $Q$. glaucoides, $Q$. peduncularis, and $Q$. salicifolia were located in the oldest part of the affected area west of the village of El Arrayanal and inoculated on 14 October 1998. This date was near the end of the wet season, which begins in June and ends in
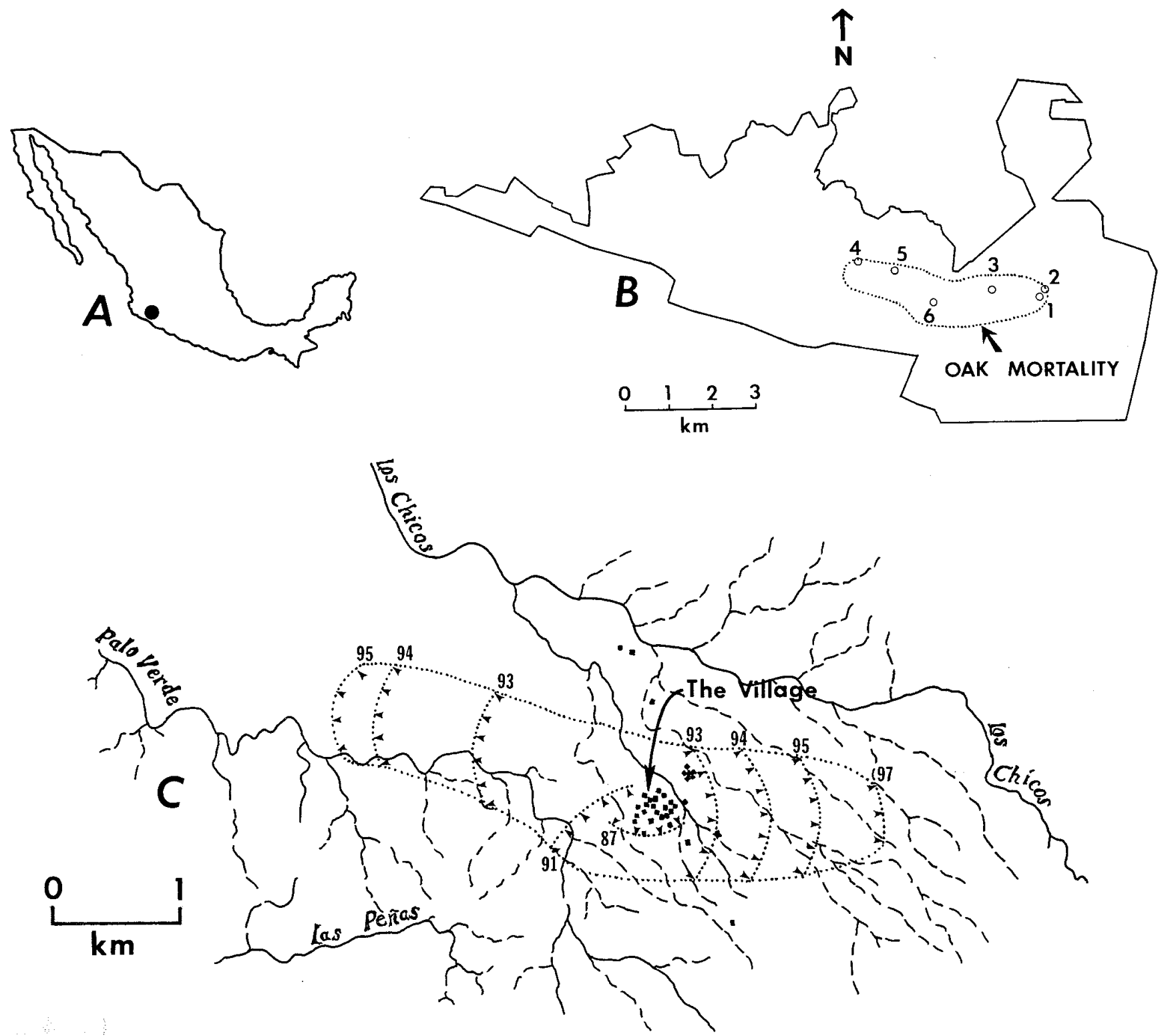

Fig. 1. (A) Map of Mexico, showing approximate location of oak mortality; (B) Map of the political boundaries of the ejido of El Arrayanal, showing approximate extent of oak mortality (dotted line) and plot locations (open circles); and (C) Map of oak mortality, showing village of El Arrayanal, permanent watercourses (solid lines), seasonal watercourses (dashed lines), and approximate locations of advancing oak mortality (arrows) from 1987 through 1997. The continuous dotted line marks the present boundary of the oak mortality area. The shorter dotted lines with arrows indicate the approximate advancing front of oak mortality during a particular year. 
November. The trees were randomly selected. They were scattered, as they were among the few asymptomatic trees remaining in the area. Average diameters $(\mathrm{cm})$ at $1.4 \mathrm{~m}$ and total heights $(\mathrm{m})$ for the three oak species inoculated were: $Q$. glaucoides: 25.0/8.9, Q. peduncularis: 21.9/8.6, and $Q$. salicifolia: $26.7 / 12.2$, respectively. While there were no significant differences in trunk diameters, $Q$. salicifolia trees were significantly taller than the other two species.

Bark plugs were removed from the trees at a height of $1.4 \mathrm{~m}$ with a 1.5 -cm-diameter punch. Agar plugs, $1.2 \mathrm{~cm}$ diameter, of the Mexican isolate (Mex. 12) of P. cinnamomi grown on 14-day-old cultures of acidified potato dextrose agar were then inserted into the wounds, one plug per wound, so that the mycelium was in contact with the cambium. The bark plugs were replaced and covered with a $6-\mathrm{cm}$ square of steril- ized cotton and a $10-\mathrm{cm}$ square of aluminum foil. The entire inoculated area was then covered with two to three layers of duct tape. A disk of sterile agar in a second wound approximately $15 \mathrm{~cm}$ to the right of the first inoculation point served as the control so that the reaction of each tree to wounding alone could be observed.

On 2 to 3 February 1999, 111 days after the trees were inoculated, the inoculated areas were debarked so that the entire resulting phloem lesion was visible. This date was approximately halfway through the dry season, and the trees were dormant, with no foliage. The length and width of phloem lesions were recorded. The phloem was then shaved off to reveal discolored xylem tissue, and the length and width of those discolorations were also recorded.

Wood chips from the phloem canker margin of 21 inoculated trees and from bleeding cankers on five adjacent non- inoculated trees of $Q$. salicifolia were removed immediately after measurements were taken. The chips were placed directly onto $\mathrm{PCH}$ medium and monitored for fungal growth. Chips were not removed from the discolored xylem for culturing.

The opposite face of each tree was inoculated in the same manner as in the October inoculations with the same isolate of P. cinnamomi. On 14 to 15 June 1999, 133 days after the trees were inoculated for the second time, resulting cankers were observed and measured as described above, with the addition that chips of discolored xylem tissues were also removed for culturing. All data were analyzed using ANOVA, Tukey's Studentized range test, and Duncan's multiple range test (8).

\section{RESULTS}

Most of the soil dilution plates prepared in Mexico yielded cultures of Trichoderma
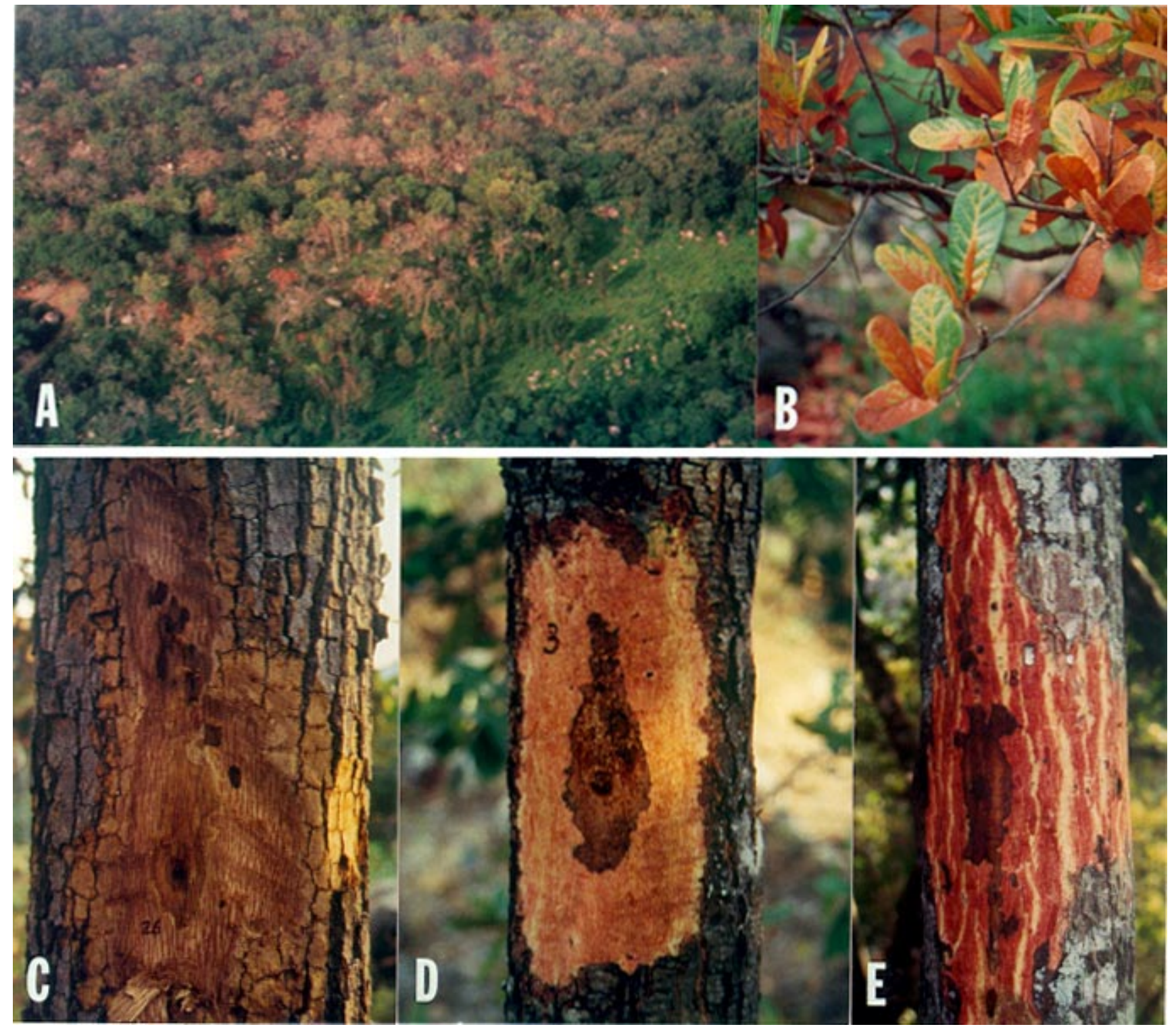

Fig. 2. Views of Phytophthora cinnamomi-caused oak mortality in Mexico. (A) Aerial photograph of portion of oak mortality area; (B) foliar discoloration on Quercus peduncularis; (C) phloem canker on Quercus glaucoides; (D) phloem canker on Quercus peduncularis; and (E) phloem canker on Quercus salicifolia. 
spp., which quickly overgrew the plates, and no isolates of either Pythium or Phytophthora. Difficulties encountered in maintaining proper temperature control during preparation of the selective medium may have impaired the antibiotic activity, which then favored growth by Trichoderma. Of the 39 fungal isolates retrieved from the soil dilutions from Clemson and placed in pure culture, 1 was lost, 10 were determined to be Pythium-group 1, 27 were Pythium-group 2, and 1 was $P$. cinnamomi, from plot 4 . Four additional cultures of what were tentatively identified as $P$. cinnamomi were overgrown by contaminants and lost.

Preliminary root-dip inoculations in liquid cultures of representatives from both Pythium groups and the surviving Mexican isolate (Mex. 12) of P. cinnamomi on 60day-old seedlings of nine oak species (Quercus alba, Q. palustris, Q. prinus, $Q$. velutina, $Q$. phellos, $Q$. coccinea, $Q$. rubra, $Q$. bicolor, and $Q$. pedunculata) revealed that only the $P$. cinnamomi isolate produced lesions on the roots of inoculated seedlings, which coincidently also killed most of the seedlings. Previous to and following inoculation, the seedlings were maintained in a tissue culture room at $23 \pm$ $2{ }^{\circ} \mathrm{C}$ under ambient lighting $(3 \pm 1 \mu \mathrm{mol})$ with cool-white fluorescent lights and a 12-h photoperiod. Only the Mexican isolate (Mex. 12) of P. cinnamomi was used in the greenhouse and field inoculations.

Greenhouse inoculation trial. Inoculation of the six seedlings of $Q$. glaucoides with the Mexican isolate (Mex. 12) of $P$. cinnamomi did not produce visible crown symptoms, but in each case, a necrotic lesion $21 \mathrm{~mm}$ in average length developed around the inoculation site on each root. As seen in cross-section, the cambium was not girdled but the necrotic area was in the form of a wedge with the widest portion at the cambium (and occupying approximately one-third of the circumference of the cambium), tapering down to a point at the pith. From 60 to $80 \%$ of the chips yielded $P$. cinnamomi, with no positive isolations from the control seedlings.

Field inoculation trials. One tree of each species was lost or vandalized before readings could be obtained. Approximately one-third of the inoculated $Q$. peduncularis trees and all of the $Q$. salicifolia trees inoculated in October exhibited evidence of dark reddish black sap bleeding from around the inoculation sites. Removal of the outer bark revealed a canker lesion in the phloem of every inoculated tree (Table $1)$. While canker width was not significantly different among the three species, average phloem canker lengths on $Q$. glaucoides $(30.1 \mathrm{~cm})$ and $Q$. peduncularis $(29.4$ $\mathrm{cm})$ were significantly greater than on $Q$. salicifolia $(10.6 \mathrm{~cm})$.

The inner bark of $Q$. glaucoides is thick and fibrous, similar to the inner hull tissues of a coconut palm fruit, and the cankered tissue changed to a light brown color upon exposure to the air. The phloem canker margin was detectable within a few seconds after removal of bark but then became barely visible as a dark but not very distinctive line (Fig. 2C). Cankers on $Q$. peduncularis and $Q$. salicifolia were a bright red to dark red with a distinctive black margin (Fig. 2D and E).

Only $6 \%$ of the chips taken from canker margins on $Q$. glaucoides yielded $P$. cinnamomi, whereas 44 and $40 \%$ were posi-

Table 1. Canker growth in Mexican oak trees (Quercus spp.) resulting from inoculations in October 1998 and February 1999 with a Mexican isolate (Mex. 12) of Phytophthora cinnamomi

\begin{tabular}{lccccc}
\hline & \multicolumn{2}{c}{ Phloem canker length $(\mathbf{c m})$} & & \multicolumn{2}{c}{ Xylem stain length $(\mathbf{c m})$} \\
\cline { 2 - 3 } \cline { 5 - 6 } Oak species $^{\mathbf{y}}$ & October & February & & October & February \\
\hline Q. glaucoides & $30.1 \mathrm{aB}^{\mathrm{z}}$ & $14.2 \mathrm{aB}$ & & $45.5 \mathrm{aA}$ & $24.3 \mathrm{bA}$ \\
Q. peduncularis & $29.4 \mathrm{aA}$ & $19.7 \mathrm{aA}$ & & $23.0 \mathrm{bA}$ & $15.9 \mathrm{bA}$ \\
Q. salicifolia & $10.6 \mathrm{bA}$ & $26.8 \mathrm{aA}$ & & $15.0 \mathrm{bA}$ & $80.4 \mathrm{aB}$ \\
\hline
\end{tabular}

y Twelve trees of each species were inoculated; however, one tree of each was lost, so data reflect 11 trees of each species.

${ }^{\mathrm{z}}$ Means within a column followed by the same lowercase letter are not different at $P=0.05$. Means within a row followed by the same uppercase letter are not different at $P=0.05$.

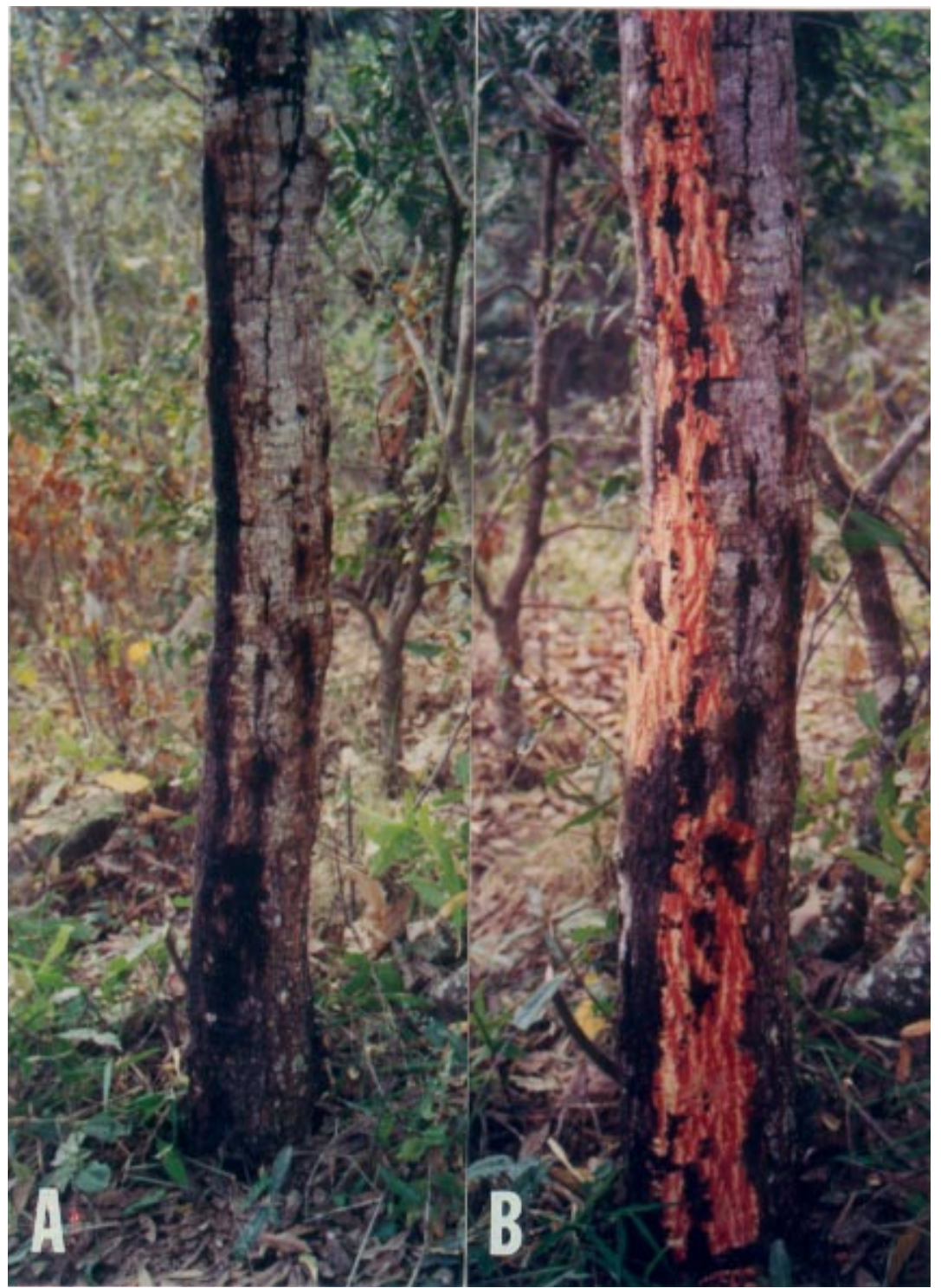

Fig. 3. Natural infection of Phytophthora cinnamomi in Quercus salicifolia. (A) External view of bleeding cankers, and (B) internal view of phloem cankers on same tree. 
that extended well above and below the inoculation point (Table 1). In Q. glaucoides, this stain length averaged $45.4 \mathrm{~cm}$, significantly greater than the 23.0 and 15.0 cm for $Q$. peduncularis and $Q$. salicifolia, respectively. The discoloration was $2.6 \mathrm{~cm}$ wide in $Q$. salicifolia, significantly less than for the other two species. Whether xylem discoloration represents only a host reaction to phloem colonization, or is also colonized, is not known, because isolations were not made from these tissues.

In the February inoculations, phloem canker lengths were $14.2 \mathrm{~cm}$ for $Q$. glaucoides, $19.7 \mathrm{~cm}$ for $Q$. peduncularis, and $26.8 \mathrm{~cm}$ for $Q$. salicifolia, but there was no statistical difference among the three oak species. Xylem stain lengths were $24.3 \mathrm{~cm}$ for $Q$. glaucoides, $15.9 \mathrm{~cm}$ for $Q$. peduncularis, and $80.4 \mathrm{~cm}$ for $Q$. salicifolia (significantly greater). There were no differences in phloem canker width or in xylem stain width among the three oak species.

Chips removed from phloem canker margins yielded an average of $35 \%$ positive isolations and an average of $6 \%$ positive isolations from discolored xylem tissues from all three oak species.

\section{DISCUSSION}

This research is significant for two reasons. The most important is that the results prove that $P$. cinnamomi is the primary cause of oak mortality in this forest in Mexico. This is also the first report of susceptibility of these three oak species to $P$. cinnamomi. Koch's postulates were performed first on a small scale in the greenhouse and then on a larger scale in the field with nonsymptomatic trees within the affected site. P. cinnamomi was recovered not only from inoculated trees, but also from symptomatic naturally infected Q. salicifolia trees.

The multitude of secondary organisms present on affected trees, such as Hypoxylon spp. and insects that attack weakened trees, had confounded our initial abilities to accurately diagnose this mortality, and for some time the incident was viewed as an example of classic oak decline, but without an adequate explanation for the presence of the advancing front. In addition, the difference in coloration of the phloem lesions between $Q$. glaucoides and the other two oak species precluded us from suspecting a common pathogenic cause. Symptoms caused by Phytophthora spp. on many plant species often are mistaken for injury from other pathogens or abiotic factors (11), partially resulting from ineffective isolation techniques (2), and have caused these important plant pathogens to be ignored or overlooked in their role in tree declines and mortality.

$P$. cinnamomi parasitizes more than 1,000 plant species, many of which are trees (2). It causes the destructive jarrah decline in Western Australia (6,9) and threatens destruction of the ancient, species-rich heath communities on that continent (13). It recently has been associated with decline of $Q$. ilex and $Q$. suber in southern Spain and Portugal $(1,12)$, Quercus spp. in California (5), and is perhaps also involved with similar declines of Quercus spp. in Italy, Morocco, and Tunisia (1). In southwestern France, the introduced $P$. cinnamomi causes a multiple basal canker on trunks of the also introduced $Q$. rubra (7) but is not generally associated with premature tree death there.

The second reason why this research is significant is that it describes the first $10+$ years of an epiphytotic caused by $P$. cinnamomi in a susceptible oak forest shortly after the epiphytotic began. This is the first documentation of the early stages of an epiphytotic following the introduction of $P$. cinnamomi into what is apparently a forest of few but very susceptible species. The exact time and place of introduction of $P$. cinnamomi into El Arrayanal may never be known for sure, although discussions with the villagers suggested that it may have been transported into the village on mango (Mangifera indica) plants that were transplanted at one of the residences. Experimental evidence (F. H. Tainter, unpublished) suggests that the understory shrub $B$. crassifolia is also susceptible to infection by $P$. cinnamomi, and its early disappearance, as noted by the villagers, may have been a forewarning of imminent oak mortality.

Observations of phloem canker development on inoculated trees in the field trials, and on naturally infected trees, indicate that the apparently susceptible $Q$. glaucoides exhibits no callus response to infection; whereas $Q$. peduncularis, and especially $Q$. salicifolia, do exhibit vigorous callus growth around phloem cankers, which may account for their apparent greater tolerance to infection.

The affected area in the ejido is still small enough so that control efforts have a reasonable chance of being successful and could well serve as a resource for demonstrations, not only for diagnosing the presence of $P$. cinnamomi in soil and symptomatic trees, but also for assessing efforts for its control. There are reports of oak decline and mortality in other Mexican states. Are these also caused by $P$. cinna$m o m i$ ? Once the investigator knows what to look for, such cases should be relatively easy to diagnose.

\section{ACKNOWLEDGMENTS}

We thank Steve Jeffers, Clemson University, for confirming the identity of the Mexican isolate of $P$. cinnamomi, and Florence Waller, Institut National Agronomique Paris-Grignon, Paris, France, for assisting with soil dilutions and identifying the Pythium groups. This research was partially supported by the McIntire-Stennis Cooperative Forestry Program. Eugene Van Arsdel, Tijeras, NM, provided supplementary funding.

\section{LITERATURE CITED}

1. Brasier, C. M. 1996. Phytophthora cinnamomi and oak decline in southern Europe. Environmental constraints including climate change. Ann. Sci. For. 53:347-358.

2. Erwin, D. C., and Ribeiro, O. K. 1996. Phytophthora Diseases Worldwide. American Phytopathological Society, St. Paul, MN.

3. Hornby, P., and Ullstrup, A. J. 1967. Fungal populations associated with maize roots. I. Quantitative rhizosphere data for genotypes differing in root rot resistance. Phytopathology $57: 76-82$.

4. Jordan, A. P., and Tainter, F. H. 1996. The susceptibility of southern Appalachian oaks to Phytophthora cinnamomi. Castanea 61:348355.

5. Mircetich, S. M., Campbell, R. N., and Matheron, M. E. 1977. Phytophthora trunk canker of coast live oak and cork oak trees in California. Plant Dis. Rep. 61:66-70.

6. Podger, F. D. 1972. Phytophthora cinnamomi, a cause of lethal disease in indigenous plant communities in Western Australia. Phytopathology 62:972-981.

7. Robin, C., Desprez-Loustau, M. L., and Delatour, C. 1992. Factors influencing the enlargement of trunk cankers of Phytophthora cinnamomi in red oak. Can. J. For. Res. 22:367-374.

8. SAS Institute. 1989. SAS/STAT User's Guide, Version 6, 4th ed. Vol. 2. SAS Institute, Cary, NC.

9. Shea, S. R., Shearer, B. L., Tippett, J. T., and Deegan, P. M. 1983. Distribution, reproduction, and movement of Phytophthora cinnamomi on sites highly conducive to jarrah dieback in south Western Australia. Plant Dis. 67:970-973.

10. Shew, H. D., and Benson, D. M. 1982. Qualitative and quantitative soil assays for Phytophthora cinnamomi. Phytopathology 72:1029-1032.

11. Tsao, P. 1990. Why many Phytophthora root rots and crown rots of tree and horticultural crops remain undetected. Eur. Mediterr. Plant Prot. Organ. Bull. 20:11-17.

12. Tuset, J. J., Hinarejos, C., Mira, J. L., and Cobos, J. M. 1996. Implicación de Phytophthora cinnamomi Rands en la enfermedad de la "seca" de encinas y alcornoques. Bol. Sanidad Veg. Plagas 22:491-499.

13. Wills, R. T. 1993. The ecological impact of Phytophthora cinnamomi in the Stirling Rabge National Park, Western Australia. Aust. J. Ecol. 18:145-159. 